\title{
Dynamic remodeling of histone modifications in response to osmotic stress in Saccharomyces cerevisiae
}

\author{
Lorena Magraner-Pardo ${ }^{1 \dagger}$, Vicent Pelechano ${ }^{2 \dagger}$, María Dolores Coloma ${ }^{1 \dagger}$ and Vicente Tordera ${ }^{1 *}$
}

\begin{abstract}
Background: Specific histone modifications play important roles in chromatin functions; i.e., activation or repression of gene transcription. This participation must occur as a dynamic process. Nevertheless, most of the histone modification maps reported to date provide only static pictures that link certain modifications with active or silenced states. This study, however, focuses on the global histone modification variation that occurs in response to the transcriptional reprogramming produced by a physiological perturbation in yeast.

Results: We did a genome-wide chromatin immunoprecipitation analysis for eight specific histone modifications before and after saline stress. The most striking change was rapid acetylation loss in lysines 9 and 14 of H3 and in lysine 8 of $\mathrm{H} 4$, associated with gene repression. The genes activated by saline stress increased the acetylation levels at these same sites, but this acetylation process was quantitatively minor if compared to that of the deacetylation of repressed genes. The changes in the tri-methylation of lysines 4, 36 and 79 of $\mathrm{H3}$ and the di-methylation of lysine 79 of $\mathrm{H3}$ were slighter than those of acetylation. Furthermore, we produced new genome-wide maps for seven histone modifications, and we analyzed, for the first time in S. cerevisiae, the genome-wide profile of acetylation of lysine 8 of $\mathrm{H} 4$.
\end{abstract}

Conclusions: This research reveals that the short-term changes observed in the post-stress methylation of histones are much more moderate than those of acetylation, and that the dynamics of the acetylation state of histones during activation or repression of transcription is a much quicker process than methylation.

Keywords: Histone modification, Chromatin, Epigenetics, Gene regulation, Genome-wide, Transcription, Osmotic stress, ChIP-Chip

\section{Background}

Evolution has selected the nucleosome structure as the universal eukaryotic genome organization. From yeast to mammals, the nucleosome structure is practically identical. The protein components of nucleosomes, histones, with a highly conserved amino acid sequence, are subjected to a wide variety of specific and reversible posttranslational modifications; i.e., acetylation, methylation, phosphorylation, deimination, ADP-ribosylation, among others (Reviewed in [1]). Besides DNA methylation, the pattern of histone modifications has also been called

\footnotetext{
* Correspondence: Vicente.Tordera@uv.es

${ }^{\dagger}$ Equal contributors

'Departament de Bioquímica i Biologia Molecular, Universitat de València,

C/Dr. Moliner 50, 46100 Burjassot, València, Spain

Full list of author information is available at the end of the article
}

epigenetic information. It is generally agreed that this information plays important roles in chromatin functions, such as activation or repression of gene transcription or nucleosome assembly during replication. However, the mechanisms by which modifications of histones can participate in these processes, especially in transcription regulation, are not yet known, although two main mechanisms have been proposed. One is that histone modifications can directly affect the nucleosomal structure or the folding properties of chromatin to facilitate DNA accessibility by allowing for trans-acting factors to gain access to DNA [2]. In the second one, histone modifications can act as a signaling system by actively participating in the recognition of, and the interaction with, trans-acting regulators factors [3-6]. Numerous discoveries made

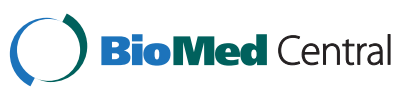


in the past decade support the notion that such modifications regulate transcription through the recruitment of effectors protein complexes (Reviewed in [7]). Obviously, both proposed mechanisms of action are not mutually exclusive.

Chromatin immunoprecipitation (ChIP) assay coupled to microarray analysis of immunoprecipitated DNA (ChIP-Chip) has become an invaluable tool for the in vivo mapping of histone modifications genome-wide [8-12]. By way of example, OJ Rando and collaborators [11] analyzed 12 histone modifications at nucleosomal resolution by hybridizing a high-density tiling microarray with mononucleosome fragments obtained after micrococcal nuclease treatment. However, the arrays used in that study covered only a small percentage of the yeast genome. A more complete map of histone modifications, describing five histone $\mathrm{H} 3$ methylations; mono-, di- and tri-methylation of lysine 4 (H3K4me1, H3K4me2, H3K4me3), tri-methylation of lysine 36 (H3K36me3) and tri-methylation of lysine 79 (H3K79me3), two histone acetylation; lysine 9 of $\mathrm{H} 3$ (H3K9ac) and lysine 14 of $\mathrm{H} 3$ (H3K14ac) and hyperacetylated histone $\mathrm{H} 4$, has been reported in [12]. The most important results obtained were that H3K9ac, H3K14ac and the hyperacetylation of $\mathrm{H} 4$ and also $\mathrm{H} 3 \mathrm{~K} 4 \mathrm{me} 3$, were found at the promoters and the $5^{\prime}$ end of transcription units, that H3K4me2 and H3K79me3 were more enriched in the middle of genes, and that H3K4me1 and H3K36me3 were found throughout the coding region to peak near the 3 ' ends of the transcription units. Moreover, all the histone modifications correlated with transcriptional activity, except for H3K4me1, H3K4me2 and H3K79me3 [12]. However, as previously discussed widely [for example, (see $[13,14])$, correlation is not causation, and the mechanism by which these histone modifications become involved in transcription needs to be known. While there are no new genome-wide studies on the acetylation status of histones in yeast, the methylation profiles of histone $\mathrm{H} 3$ obtained in [12] have subsequently been corroborated by other authors using higher density chips probes [15-17] or ChIP-seq [18,19].

Despite the power of ChIP-Chip for mapping global patterns of histone modifications, the above-cited studies generally provide only a static picture of levels of modifications under a given set of conditions. However, in order to understand the role of histone modifications in transcriptional regulation and the causality between the two processes, it is paramount to study both process dynamically. To address this question, we used tiling DNA microarrays to analyze eight genome-wide specific histone modifications; H3K9ac, H3K14ac, acetylation of lysine 8 of $\mathrm{H} 4$ (H4K8ac), H3K4me1, H3K4me3, H3K36me3, di-methylation of lysine 79 of $\mathrm{H} 3$ (H3K79me2) and H3K79me3; before and after a physiological perturbation (osmotic stress for $10 \mathrm{~min}$ ) that causes genome-wide transcriptional changes. We selected these acetylation sites because they are representative of the target of the three histone acetyltransferases which have been related to transcription activity; Gcn5p [12,20,21], Sas3p [22] and Esa1p [12,21,23-25]. Methylation sites were selected because the methylation of the histones in S. cerevisiae is carried out by three known histone methyltransferases (Set1p, Set2p and Dot1p) that modify H3K4 [8,26-31], H3K36 [32] and H3K79 [33-36], respectively. This paper demonstrates that gene repression was accompanied by a dramatic drop in acetylation, mainly at the transcription start site (TSS) and its surroundings, whereas the profiles of methylation hardly changed, and that only slight decreases were observed along the transcribed region, with modifications correlating positively with transcription. Gene activation was accompanied by an increased level of acetylation at the TSS, but it was less intense than that of the deacetylation of repressed genes. Once again, only a moderate increase in the methylations correlating with transcription was noted. We also analyzed, for the first time in S. cerevisiae, the genome-wide profile of a histone modification, which has been related to transcription regulation [37]: H4K8ac.

\section{Results and discussion}

\section{A new genome-wide and comprehensive histone modification map for yeast}

As a first step to study chromatin dynamics, we produced new genome-wide maps for the presence of three histone acetylations under standard growing conditions using high tiling density arrays. The precision of the obtained data allowed us to incorporate important nuances into previous studies. We also analyzed, for the first time in $S$. cerevisiae, the genome-wide profile of H4K8ac. Figure 1 (left panels) shows the profile of the H3K9ac (Figure 1a), H3K14ac (Figure 1b) and H4K8ac (Figure 1c) modifications. We employed a graphical (real-length) representation, where profiles were centered on the actual TSS [38], and the data for each probe corresponded to the distance from the TSS up to the total transcript length, with a maximum of $3000 \mathrm{bp}$. In this type of representation, the represented number of genes lowered as we moved downstream along the transcribed region. Therefore noise increased, but the structure of the actual profile was maintained. As expected, our general results were consistent with those previously described for H3K9ac and H3K14ac [12]. We also employed a classical representation of genome-wide data using a metagene profile of widespread use $[12,17,39,40]$, where genes are expanded or compressed to fit onto a hypothetical gene of average length (Additional file 1: Figure S1). The comparison made of both types of graphs raised some intriguing questions. For instance, the metagene profile of H3K9ac, 

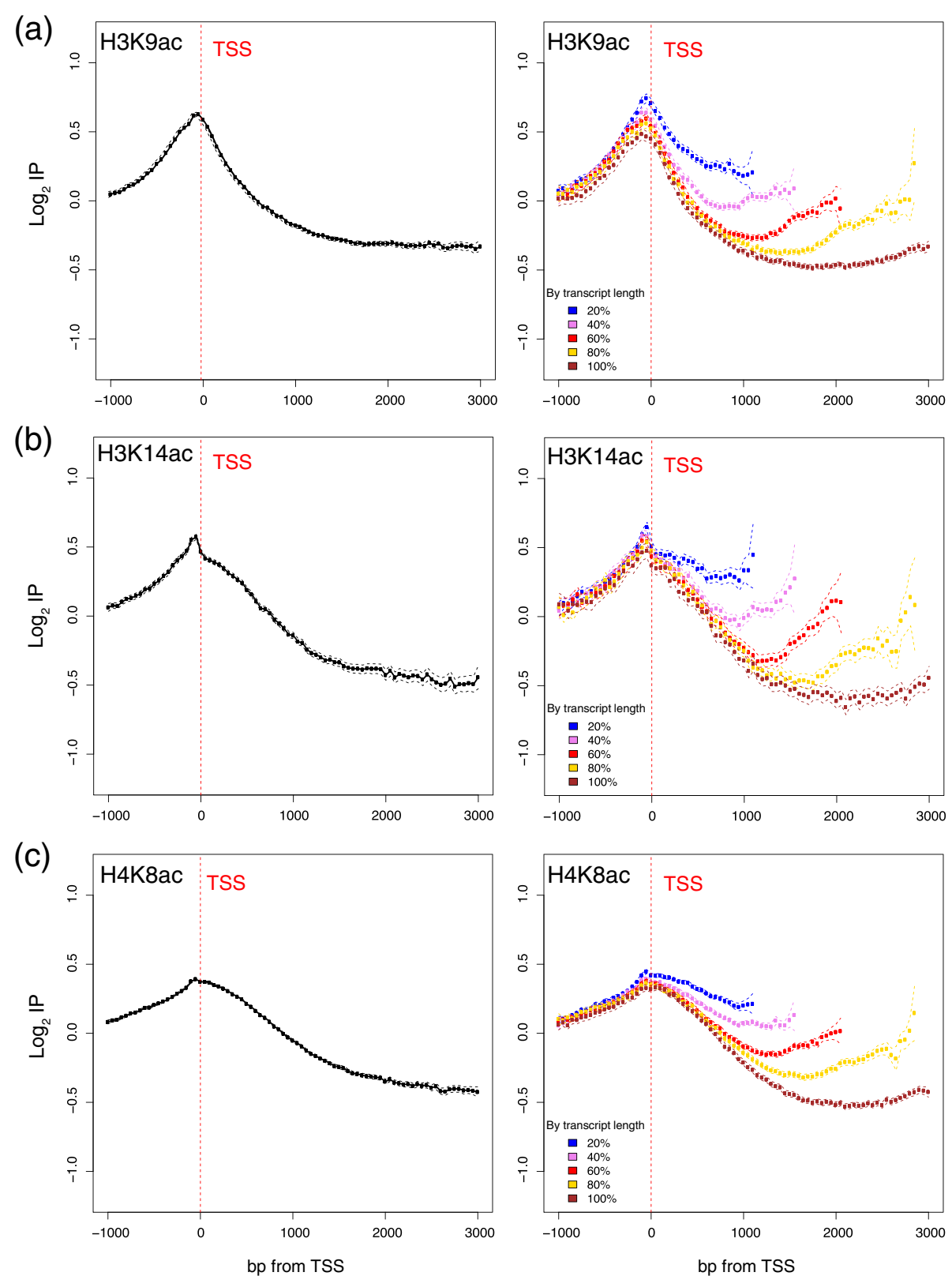

Figure 1 Genome-wide profiles of histone acetylation. The levels of H3K9ac (a), H3K14ac (b) and H4K8ac (c) in relation to the levels of core histone $\mathrm{H} 3(\mathbf{a}, \mathbf{b})$ or $\mathrm{H}_{4} \mathbf{( c )}$, genome-wide, are shown. The log2 values of the specific immunoprecipitation of the modified histone were represented in relation to the immunoprecipitation of the core histone (i.e., $\mathrm{H} 3$ or $\mathrm{H} 4$ ). For the real-lengths representation (left panels), the profiles were centered on the actual TSS [38] and the data for each probe corresponded to their real distance from the TSS for each gene, from 1000 bp upstream up to the total transcript length, to a maximum of $3000 \mathrm{bp}$ downstream. Probes were binned to $100 \mathrm{bp}$. The mean and confidence intervals for the means (t-test, 95\% confidence) were plotted. Each experiment compared a ChIP with a histone modification antibody to a control ChIP with a core histone antibody. Genes were divided into quintiles according to their transcript length (right panels).

H3K14ac and H4K8ac (Additional file 1: Figure S1) shows that these modifications peaked just before the TSS of the genes, and also at the end of the gene. However, when the data were represented in their real length, the increase at the end of the gene disappeared (left panels of Figure 1). To dissect this difference observed between the two representations, we used the real-length representation on sets of genes of different lengths. As the right panels of Figure 1 depict, an actual increase in the signal levels at the 3 ' region was observed for all the transcript lengths and acetylation marks, except for the group containing the shortest transcript for the H3K9ac mark and, to a 
lesser extent, the longer transcript for the three marks. The increase in signal toward the end of the genes was not observed in this representation for long genes as their transcription termination sites are spread from around 2.2 to $15 \mathrm{~Kb}$ from the TSS and both elongation and terminations marks co-exist at $3 \mathrm{~Kb}$. The 3 ' accumulation of these marks, typically associated with the start of transcription, suggests that they may also be implicated in the final process stage, or may be caused by neighbor promoters or gene loopings with their own promoter. It is also noticeable that the H3K9ac, H3K14ac and H4K8ac levels were inversely related to their length. The fact that the levels of all these modifications were directly related to transcriptional activity can be explained by the major transcriptional activity of short genes if compared to long genes on average, as previously described $[41,42]$.

Both H3K9ac and H3K14ac peaked at the probes located between the TSS and -100 bp (Figure 1a,b). This location corresponds precisely to the nucleosomedepleted region (NDR) associated with the TSS [43,44]. However, as we measured the histone modification levels with the levels of the same unmodified core histone [12], this represented only the relative presence of the modification independently of actual nucleosome abundance. Although the presence of an NDR in the promoters regions is widespread (i.e., affecting mainly TATA-less genes, which represent around $80 \%$ of the total), a considerable number of genes exhibited a more variable promoter architecture (Reviewed in [14]). We hypothesized that the poor presence of histone at this position implies that these data are highly influenced by their neighbors; that is, by nucleosomes- 1 and +1 . In this context, it has been recently proposed that both promoterbound nucleosomes assume discrete configurations, which not only define the open or closed states of promoters, but distinguish between the "on" and "off" expression states [45]. As the opening and closing of the promoter is a dynamic process, one interesting proposal is that the histone modifications of these nucleosomes are involved in switching between the on and off promoter states.

The H4K8ac profile, which has not been mapped genome-wide in yeast, was similar to that of the abovedescribed H3K9ac and H3K14ac, although the association was not as strong as that observed for H3K9ac and H3K14ac (Figure 1c). Strikingly, the peak of H4K8ac, which we obtained at the TSS, contradicts previously reported results [11], which describe a two-nucleosome hypo-acetylated domain for H4K8, H4K16 and H2BK16 adjacent to the start codons.

We also produced genome-wide maps for H3K4me1, H3K4me3, H3K36me3, H3K79me2 and H3K79me3 (Additional file 2: Figure S2 a-e) under standard growing conditions. As expected, our general results were consistent with those previously described. [12,15-19].

\section{Modification of histones in gene clusters}

We also investigated the modifications associated with a particularly interesting set of genes. A well-known example for the groups of genes associated with a specific profile of histone modifications is the presence or absence of the canonical TATA box in their promoter. We represented (Figure 2a and Additional file 3: Figure S3) all the profiles of the modifications of the histones analyzed in this work separately for both the TATA genes and the TATA-less genes. It is remarkable that for all the modifications studied, peaks were higher for the TATAless genes (as seen in Figure 2a for H3K9ac), with the expected exception of H3K4me1, for which the opposite occurred. The TATA genes are typically stressresponsive and regulated by a variety of chromatin remodeling factors (reviewed in [14]), and this was also the case under our cell growth conditions (exponential growth in rich media) as the median expression of the TATA genes was higher than in the TATA-less ones [41]. Such differences should be due to their different promoter architecture.

In addition to classifying genes according to their promoter structure, BJ Venters and BF Pugh classified them in terms of the differential accumulation of RNA pol II along the promoter and the coding region [46]. Thus, these authors identified three groups of yeast genes in which RNA pol II was enriched at the promoters in relation to the gene body (Group 1), enriched immediately downstream of the promoters (Group 2), or spread throughout the genes (Group 3). These authors suggested that this subgenic location can reflect ratelimiting steps during transcription, including initiation, elongation and termination. We represent the histone modifications profiles for these three groups in Figure $2 \mathrm{~b}$ and Additional file 4: Figure S4. In order to correctly interpret these graphs, it is important to consider that, on average, the genes of Group 1 were the least active (i.e., smaller total amount of RNA pol II present along the gene), the genes of Group 3 were the most active (i,e., more RNA pol II present along the gene), and that our data were always normalized by core histones. It is not surprising, therefore, that the genes in Group 1 showed a less intense H3K9ac peak at the TSS than the other genes (Figure 2b). Another interesting point is that the Group 3 genes, which displayed a comparatively even distribution of RNA pol II across their genes, or even enrichment toward the 3' end, showed a clear increase in H3K9ac (Figure 2b), H3K14ac, H4K8ac and H3K79me2 (Additional file 4: Figure S4) in the body of genes if compared to the other genes. This scenario suggests that the presence of RNAPII results in the increased recruitment of HATs and Dot1, which enhance these modifications. It is also noteworthy that the presence of RNA pol II poised at the promoters in the genes 

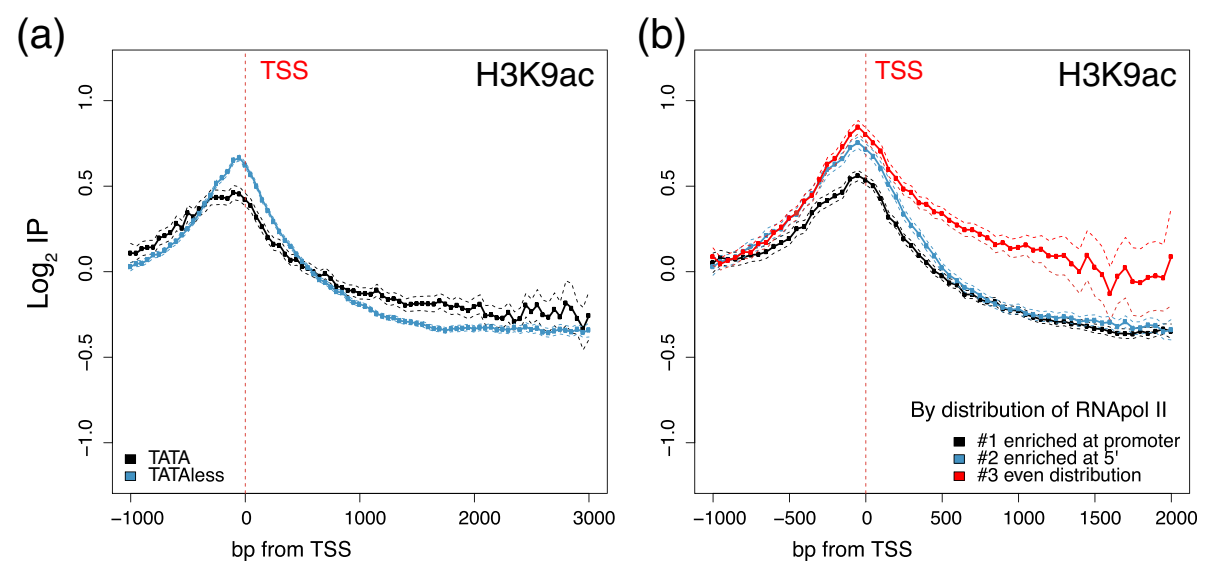

Figure $2 \mathrm{H3K9ac}$ profiles of a set of genes. The real-lengths representation of the profile of H3K9ac of the genes in relation to the levels of core histone $\mathrm{H} 3$ grouped according to presence or absence of a TATA box (a), or according to the distribution of RNA pol II [46] on the gene (b). The $\log 2$ values of the specific immunoprecipitation of the modified histone were represented in relation to the immunoprecipitation of core histone H3.

of Group 1 was accompanied by an increase in signals H3K4me1 and H3K36me3 at the promoters if compared to the other groups of genes (Additional file 4: Figure S4). It has also been reported that H3K4me1 does not require the ubiquitination of histone $\mathrm{H} 2 \mathrm{~B}$, suggesting a Paf1-independent targeting of Set1 to the coding region of active genes [47]. An increased H3K4me1 signal in the promoters with poised RNA pol II could result from this targeting of Set1, while an increase in H3K36me3 suggests that Set $2 p$ is possibly present, together with RNA pol II, in this early process step.

\section{Correlation between histone modifications and the transcription rate, mRNA amount and RNA pol II presence} Transcriptional activity is tightly linked to histone modifications. However, transcriptional activity can be measured by different indicators. The simplest indicator of transcriptional activity is presence of mRNA. Nevertheless, more direct indicators of transcriptional activity, such as presence of RNA pol II in the body of genes [48] or nascent RNA production, are also available [41]. Many researchers have also utilized a data set [49], which represents the indirect calculation of the rate of appearance of mature mRNAs in the cytoplasm. Yet all these measures (i.e., mRNA amount, RNA pol II occupancy, nascent transcription rate and indirect transcription rate) reflect different biological realities. We compared all four data sets with the level of the eight histone modifications studied in both the promoters region and the ORFs in Additional file 5: Table S1. The results indicate that all the analyzed modifications correlated positively with the four data sets employed, except for H3K4me1, which correlated negatively, as expected [12]. Moreover, correlations were always better for RNA pol II occupancy than for the other data sets, and the nascent TR data sets generally correlated better than the indirect data sets, especially with H3K36me3, a chromatin mark that has been directly related with transcription elongation [12]. The worst correlation of all was noted for amounts of mRNA (Additional file 5: Table S1), indicating that post-transcriptional processes, such as mRNA stability, must be taken into account for correct data interpretation [41].

To acquire information about the particular positions at which histone modification can recruit transcription factors or can be modified as a result of transcription, we computed the precise location along the gene where each histone modification better correlated with transcription. Figure 3 shows the Spearman rank correlation between the eight histone modifications and the RNA pol II occupancy obtained at different gene locations. Several important conclusions can be drawn from this figure. First, H3K9ac, H3K14ac and H4K8ac show a profile with a peak centered at the TSS, which decreased downstream. While this figure depicts a less pronounced H3K14ac peak, we performed similar experiments in other yeast strains. The peak obtained for H3K14ac was similar to that of H3K9ac, and was only slightly lower in height (results not shown). Second, H3K4me3 and H3K36me3 exhibited a practically identical profile, and it was not possible to distinguish if one modification preceded the other, or vice versa. H3K79me3 displayed a profile of positive correlations with a similar shape to that of H3K4me3 or H3K36me3, but of less intensity. This result contradicts a previous study which found no correlation between the level of H3K79me3 and transcriptional activity [12]. The discrepancy between these two genome-wide profiling studies in yeast, and also in other eukaryotes, has been attributed to the different chromatin preparation methods used and, more specifically, 

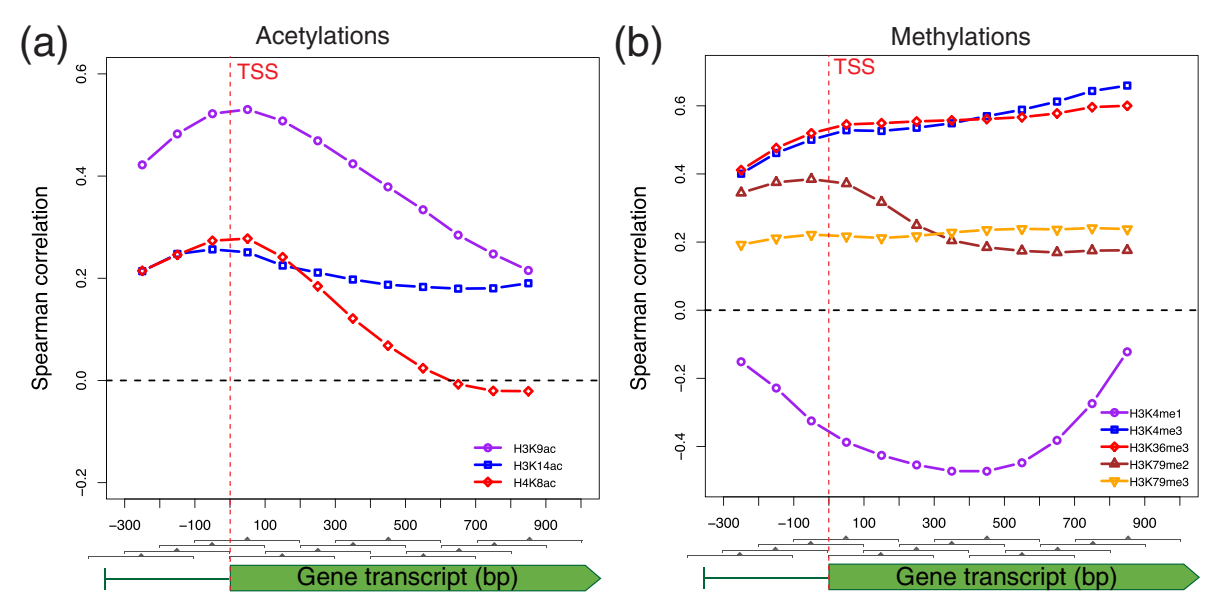

Figure 3 Correlation between histone modifications and RNA pol II occupancy at different gene locations. The Spearman rank correlation among the eight histone modifications and RNA pol II occupancy. Gene regions were split using a sliding window of 300 bp along the ORFs (from the promoter regions to the internal regions) Histone acetylations (a) and histone methylations (b). The Spearman correlations between whole gene RNApol II occupancy (Rpb3) [48] and local histone modification were computed for each region.

to the presence or absence of sodium dodecyl sulfate in formaldehyde-cross-linked chromatin [50]. As recently discussed however [49], analyses of mouse, fly, and human genome have revealed that H3K79 methylation is indeed a marker of active transcription, which thus confirms our results in yeast. Finally, as in the gene modifications profiles, H3K79me2 once again showed a very similar profile of positive correlations to those of the histone acetylation peaking at the TSS.

Our results indicate that the histone modifications which better correlate with transcription activity are those of H3K4me3 and H3K36me3 (Spearman correlation of 0.659 and 0.600 , respectively), which is in agreement with previous reports [11,12], and that both modifications can be considered chromatin marks related with transcription elongation (Figure 3). H3K79me3 modifications can also be considered chromatin modifications related with transcription elongation, but of less magnitude. The correlation of H3K4me1 with RNA pol II was negative and gave a high absolute value: $-0,473$ between +300 and $+600 \mathrm{bp}$ in the ORF. According to our results, the most important chromatin modification associated with active promoters was $\mathrm{H} 3 \mathrm{~K} 9 \mathrm{ac}$, which reached values of 0.530 between -100 and +200 bp. H3K14ac, H4K8ac and, strikingly, H3K79me2 modifications, can also be considered chromatin modifications in relation to active promoters, but of less magnitude.

\section{Changes in the modification of histones during the activation or repression of genes}

The key question as to the function of histone modifications in transcription regulation is whether or not they are the cause or the consequence of the process itself $[1,13,14,51]$. In order to gain new insights into this central issue, we studied the histone modifications associated with the drastic change in transcription activity associated with osmotic stress. This is an ideal condition as the molecular mechanism is well-known (reviewed in [52]), and also because independent transcriptomic response data sets are available [53-55]. For our study, we chose the data relating to changes in transcription rate [55] obtained from genomic run-on experiments [56], which offer the chance to study the direct link between transcriptional activity and chromatin (unlike the mRNA abundance data sets which require the accumulation of mRNA molecules). Furthermore, the number of genes that are up- and down-regulated by osmotic stress is large enough to reduce noise and allows the identification of statistically relevant trends. In our case, we used 248 genes defined as being up-regulated and 400 down-regulated genes (Additional file 6: Table S2) [55]. It has also been reported that the activation or repression of osmotic stress genes can be carried out by several mechanisms, which include the recruitment of chromatin-modifying activities (reviewed in [52]). Taken together, these findings suggest that histone modifications can play an important role, at least in the activation of the genes induced by osmotic stress. Finally, osmotic stress is a quick process in which a transcriptional response is obtained in only $10 \mathrm{~min}[55,57]$. Therefore, we performed a chromatin immunoprecipitation analysis for eight specific histone modifica tions; H3K9ac, H3K14ac, H4K8ac, H3K4me1, H3K4me3, H3K36me3, H3K79me2 and H3K79me3; before and after osmotic stress $(0.4 \mathrm{M} \mathrm{NaCl})$ produced by adding a small volume of a concentrated $\mathrm{NaCl}$ solution to the yeast culture $10 \mathrm{~min}$ before cross-linking with formaldehyde. Specifically, we measured the histone modification levels in relation to the levels of the same unmodified core histone. 
The up- and down-regulated genes followed a divergent regulation of the acetylation level upon stress treatment. Figure 4 shows the profiles of H3K9ac, H3K14ac and $\mathrm{H} 4 \mathrm{~K} 8 \mathrm{c}$ for the genes that were up- or down-regulated in response to osmotic stress before (left panels) and after (right panels) stress. As seen, the up- and down-regulated genes already exhibited an opposite profile before osmotic stress was applied. This is consistent if we consider that the stress-induced genes generally displayed little or no activity before stress and, vice versa, that the genes repressed by stress were more active before stress. The poststress situation drastically changed. As seen in the right panels, the H3K9, H3K14 and H4K8 acetylations of the down-regulated genes significantly decreased at the TSS and in its surroundings. In fact, the acetylation pattern of the three modifications was similar to that of the stressed

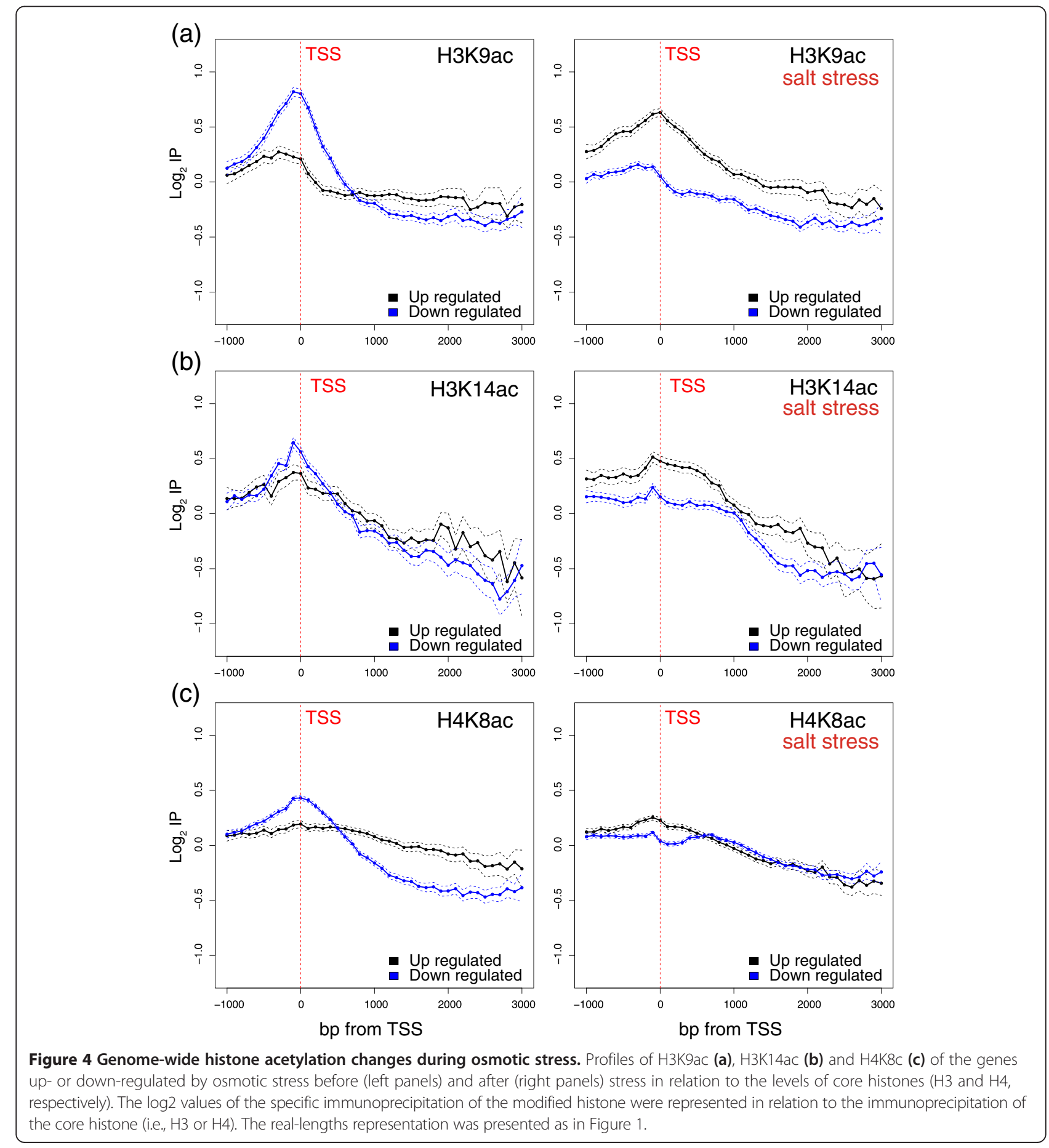


up-regulated genes before stress, or was even lower. The profiles of the H3K9, H3K14 and H4K8 acetylations of the genes up-regulated after stress also underwent important changes as their acetylation level at the TSS increased. However, none of the three sites reached the acetylation level of the stressed down-regulated genes before stress. This is perhaps because these genes did not reach a similar transcription rate level to that of the down-regulated genes before stress. These results demonstrate that transcription repression is associated with a quick deacetylation of H3K9, H3K14 and H4K8 at the TSS. To confirm this, we focused on a particular group of genes, ribosomal proteins (RP), which are, with the group of histones, the highest transcribed group of yeast genes under normal growth conditions [41], but are quickly repressed transcriptionally upon osmotic stress [53,55]. As expected, Figure 5 shows that the H3K14ac and H3K9ac levels of the RP genes were very high before stress (note that the scales in Figures 4 and 5 differ). As seen in the right panels of Figure 5, the acetylation profiles dramatically dropped and reached a similar acetylation level to that of the remaining genes in only $10 \mathrm{~min}$. This result is consistent with the fact that histone acetylation is a rapidly reversible process and that acetyl groups turned over rapidly in vivo, with half-lives in the order of minutes [58], thus allowing rapid gene expression changes in response to signals. The $\mathrm{H} 3 \mathrm{~K} 9 \mathrm{ac}$ profile is especially interesting as it did not follow the same pattern as the remaining genes did because its maximum was presented before stress in the transcribed region in nucleosomes +1 and +2 , while other genes displayed their maximum immediately before the TSS. It is precisely in nucleosomes +1 and +2 where the major decrease of H3K9ac took place after stress, suggesting that the H3K9ac of these nucleosomes may play an important role in maintaining the active state of these genes or, alternatively, that its deacetylation is important to switch off their inactivation. Something similar occurred with H4K8ac, but much less intensely. In this context, +1 to +3 nucleosome spacing has been described to be significantly shorter over RP genes than over other gene types, and that polymerase loss results in the relaxation of +1 to +3 spacing in RP genes [59]. It has also been shown that the chromatin structure of RP genes in their $5^{\prime}$ part plays a differential role during transcription elongation [60]. One reasonable hypothesis is that the H3K9ac of these nucleosomes may play a fundamental role in maintaining the special active chromatin architecture of these genes or, alternatively, that its deacetylation is important for them to be switched off, hence their relaxation.

The transcription activation of genes is associated with the acetylation of all these three sites at the TSS. Nevertheless, this process seemed less intense, widespread or slower than that of the deacetylation of the down-regulated genes. Both activities (deacetylation of down-regulated genes and acetylation of up-regulated genes) required the presence of the respective enzymes. Our results cannot explain the reported recruitment of Rpd3 [57], a histone deacetylase involved in deacetylating most core histone sites, except lysine 16 of $\mathrm{H} 4$ [61] to osmoresponsive promoters to induce the gene expression of up-regulated genes. In fact, it seems contradictory that the activation of the genes required the recruitment of a histone deacetylase to finally increase its acetylation, unless the sites deacetylated by Rpd3 differed from those analyzed in this study. Conversely, the observation that SAGA is recruited to the osmostres up-regulated genes [62] is in agreement with the increased acetylation level of the genes we found. Gcn5p is a SAGA subunit with histone acetyltransferase activity with specificity for H3K9 and H3K14. Hence, Gcn5p may be responsible for the increase in acetylation at these lysine residues, but is limited to the TSS region. The slight increase in H4K8 acetylation observed may be attributed to another histone acetyltransferase activity specific for this lysine, perhaps Esa1p.

Methylation of histone $\mathrm{H} 3$ in $S$. cerevisiae has also been related to transcription, mainly $\mathrm{H} 3 \mathrm{~K} 4 \mathrm{me} 3$ at promoters and H3K36me3 in the coding region [12]. In our study, we measured the changes of the H3K4me1, H3K4me3, H3K36me3, H3K79me2 and H3K79me3 levels brought about by the repression or induction of genes. Figure 6 shows the profile of these histone modifications of genes, which were up- or down-regulated with osmotic stress before (left panels) and after (right panels) stress. Before stress, H3K4me3, H3K36me3, H3k79me2 and H3K79me3 showed a higher modification level in the down-regulated genes than the in the up-regulated ones. With H3K4me1, in which a negative correlation has been reported [12], the reverse effect occurred. Yet the most remarkable point of this experiment was the comparison made of the profiles before and after stress. The methylation levels of the analyzed lysine residues did not change drastically, quite unlike what happened in acetylation. Thus, the methylation profiles of the up- or down-regulated genes barely changed after $10 \mathrm{~min}$ of stress, with only slight increases found in the up-regulated genes and slight decreases in the down-regulated genes noted along the transcribed region in $\mathrm{H} 3 \mathrm{~K} 4 \mathrm{me} 3$, H3K36me3, H3k79me2 and $\mathrm{H} 3 \mathrm{~K} 79 \mathrm{me}$. It is also worth noting that these changes were not limited to either the TSS in H3K4me3 or the transcribed region in $\mathrm{H} 3 \mathrm{~K} 36 \mathrm{me}$, but that both changes occurred in the promoter and the wide region of the $5^{\prime}$ transcribed region. H3K79me2 displayed a particular behavior because the changes caused by stress, mainly in the repression of the down-regulated genes, were located principally near the TSS. It seems that the profiles of both the up- and down-regulated genes tended to 

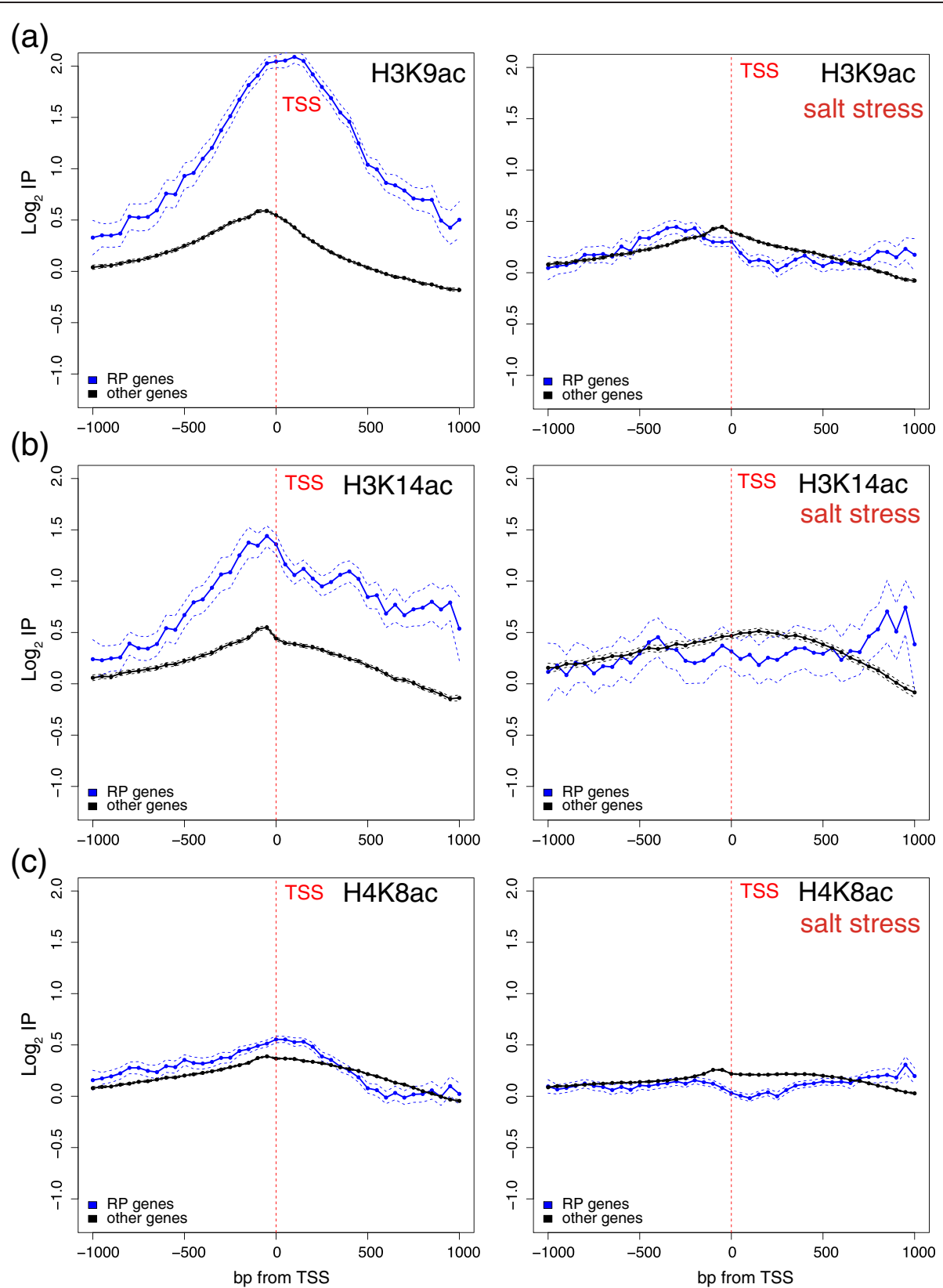

Figure 5 Histone acetylation changes on RP genes during osmotic stress. Profiles of H3K9ac (a), H3K14ac (b) and H4K8c (c) of the RP genes or the remaining genes before (left panels) and after (right panels) osmotic stress in relation to the levels of core histones ( $\mathrm{H} 3$ and $\mathrm{H} 4$, respectively). The log2 values of the specific immunoprecipitation of the modified histone were represented in relation to the immunoprecipitation of the core histone (i.e., H3 or H4). Data were represented as in Figure 4, except that the represented region went from 1000 bp upstream of the TSS to a maximum of $1000 \mathrm{bp}$ downstream. Probes were binned to $50 \mathrm{bp}$.

generally approach each other after stress. Taken together, these results strongly suggest that the trimethylation of H3K4, H3K36 and H3K79 across the transcribed region is a process that most likely stems from the presence or passage of RNA pol II, as described by other authors. To determine whether the reverse process, that is, the de-methylation of these lysine residues during the repression of the down-regulated genes, was slow or fast, we re-focused on RP genes. Figure 7 shows the profiles of H3K4me3, H3K36me3, H3K79me2 and H3K79me3 of the RP genes as compared with the remaining genes both before (left panels) and after (right panels) stress. Once again, we observe that all four modifications were very intense before stress (left panels). Repression of these genes by stress lowered all the modifications but, in this case, not at the level of 

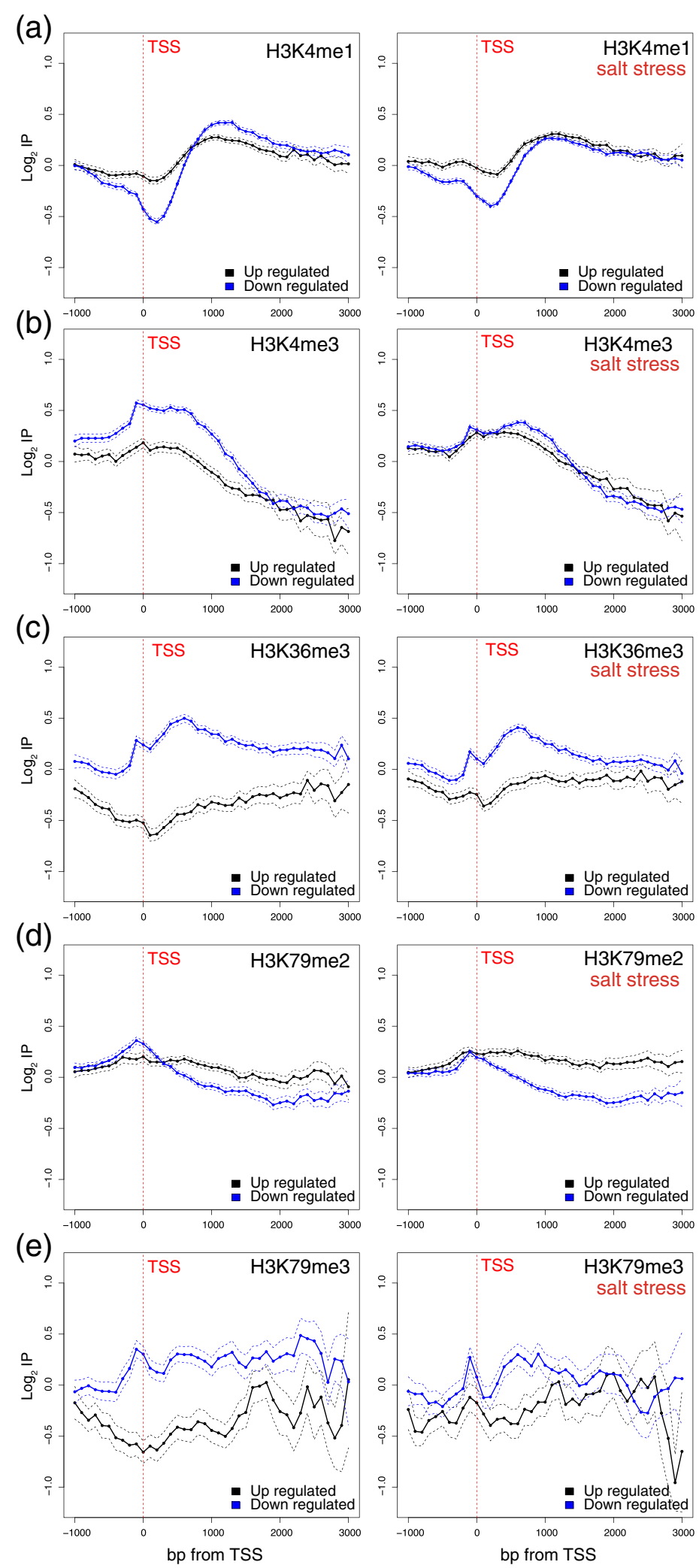

Figure 6 (See legend on next page.) 
(See figure on previous page.)

Figure 6 Genome-wide histone methylation changes during osmotic stress. Profiles of H3K4me1 (a), H3K4me3 (b), H3K36me3 (c),

H3K79me2 (d) and H3K79me3 (e) of the genes up- or down-regulated by osmotic stress before (left panels) and after (right panels) stress in

relation to the levels of core histone $\mathrm{H} 3$. The log2 values of the specific immunoprecipitation of the modified histone were represented in relation to the immunoprecipitation of core histone H3. Data were represented as in Figure 4.

the remaining genes. Furthermore, H3K4 and H3K79 seemed to be de-methylated more intensely or, perhaps, more rapidly than H3K36. Alternatively, it was possible to replace the methylated histones with other non methylated ones in a process mediated by chromatin remodeling complexes.

While this manuscript was being prepared, a genomewide mapping of five histone modifications, including H3K4me3, H3K36me3 and H3K14ac, during diamide stress was published [63]. Our results agree with the genome-wide changes described in this recently published study. However, these authors also found that the H3K4me3 levels increased at the $5^{\prime}$ ends of a substantial number of diamide-repressed genes during their repression, including RP genes [63], which clearly contradicts our results. The distinct chromatin changes observed in the RP genes during repression can be explained only if both osmotic and diamide stresses operate via distinct pathways.

The timing of the acetylation and methylation processes, shown herein, suggests some major consequence. Thus, several complexes with histone acetyltransferase activity, such as NuA3 [64] or SAGA [65], have been described to bind during gene activation to H3K4me3 to promote their histone acetyltransferase activity toward H3K14. Given our results, it is difficult to accept that the (barely perceptible) changes in the levels of H3K4me3 produced during the activation of transcription in the up-regulated genes can mediate the downstream effects affecting the acetylation state of $\mathrm{H} 3$ in a short time when the opposite is much more likely. Consistently with our results, the mutation of histone H3K14 has been reported to result in a loss of H3K4me3 in bulk histones [66], or more recently, that histone H3K4 demethylation is negatively regulated by H3K14 acetylation in Saccharomyces cerevisiae [67].

\section{Conclusions}

Our mapping data of the modifications occurring under standard growing conditions generally agree with previous studies [12], although we also observed several unexpected behaviors (i.e., an increase in the H3K9ac, H3K14ac, H4K8ac and H3K79me2 signal levels at the 3' region with longer genes). In fact, it is strikingly that all the genome-wide features of H3K79me2 described herein are similar to those of acetylation.

To date, most chromatin state maps have provided static pictures of histone modifications. However, the participation of modifications of histones in regulating gene expression must occur as a dynamic process. In this research, we have conducted a study that has focused on the genome-wide changes of several relevant histone modifications associated with the major transcriptional reprogramming caused by osmotic stress. We report herein that the most striking change is the quick deacetylation of $\mathrm{H} 3 \mathrm{~K} 9, \mathrm{H} 3 \mathrm{~K} 14$ and $\mathrm{H} 4 \mathrm{~K} 8$, associated with the repression of genes. Activated genes increase the acetylation levels at these same sites, but the acetylation process of activated genes seems smaller in quantitative terms to that of the deacetylation of repressed genes. The changes noted in the acetylation state of osmoregulated genes are caused mainly in the transcription start site (TSS) region. As expected, the trimethylation of H3K4, H3K36 and H3K79, and also the di-methylation of H3K79, of the activated or repressed genes also changed by increasing and decreasing, respectively. However, the short-term changes observed in the post-stress methylation of histones are much more moderate than those of acetylation. This research work, besides that recently reported while preparing this manuscript [63], is the first genome-wide study of dynamic changes in histone modifications in response to global transcriptional reprogramming in yeast. The observed changes support the acetylation hypothesis given the possibility of them acting as signals involved in triggering the process of activating or repressing transcription. The moderate changes noted in the methylation of histones seem to be a process that occurs as a result of presence of RNA pol II. Our results also indicate that the acetylation state of histones during transcription activation or repression is a much quicker process than methylation.

Here we show that dynamic studies need to be done to gain a better understanding of the relationship between chromatin and transcription. We foresee that an understanding of chromatin will strongly benefit from an even more detailed study into the dynamics of chromatin modifications.

\section{Methods}

Yeast strain and antibodies

The $S$. cerevisiae strain used in this study for the genome-wide location analysis was BY4742, derived from S288C.

The experiments described in this study compared ChIP with a histone modification antibody to a control 
(a)

(b)
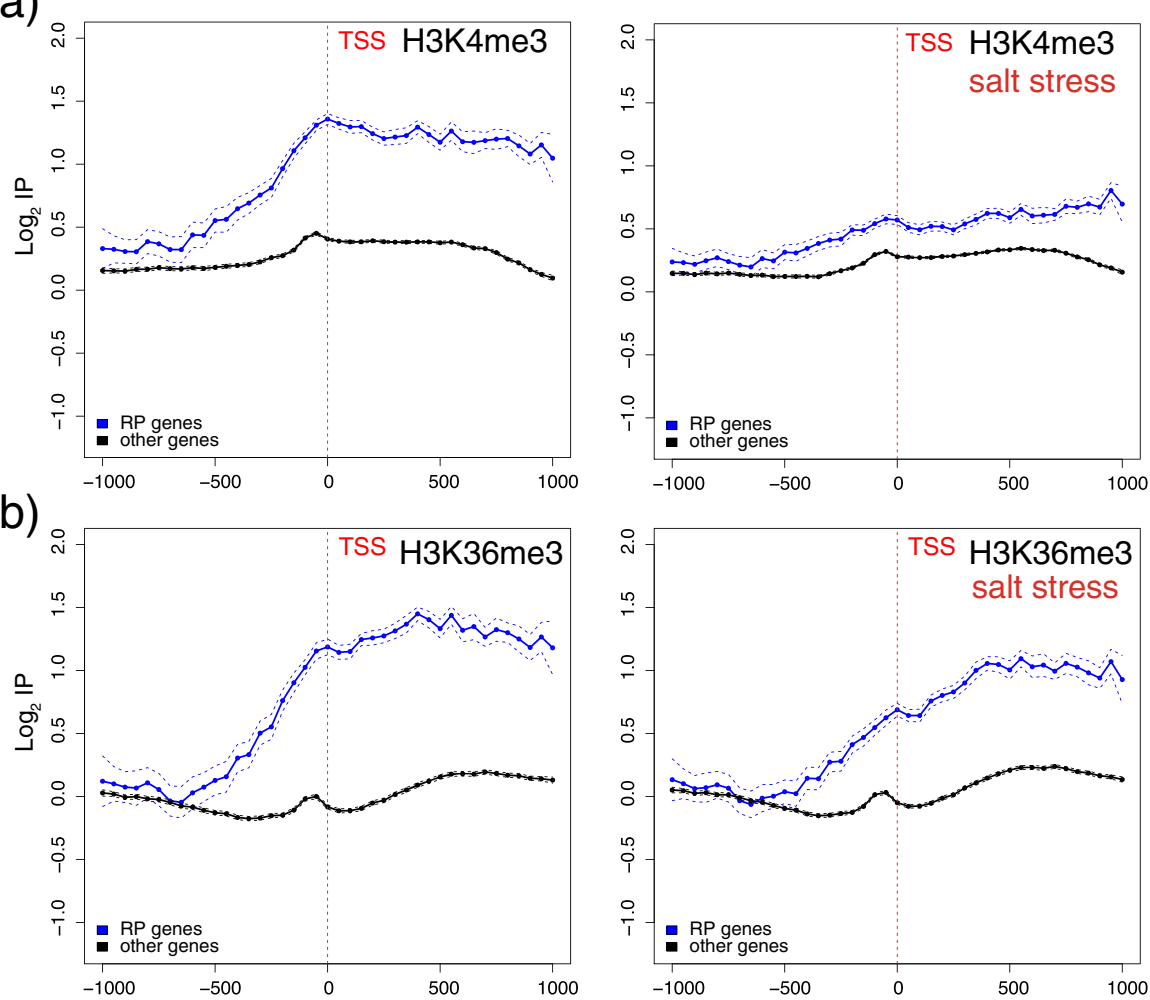

(c)

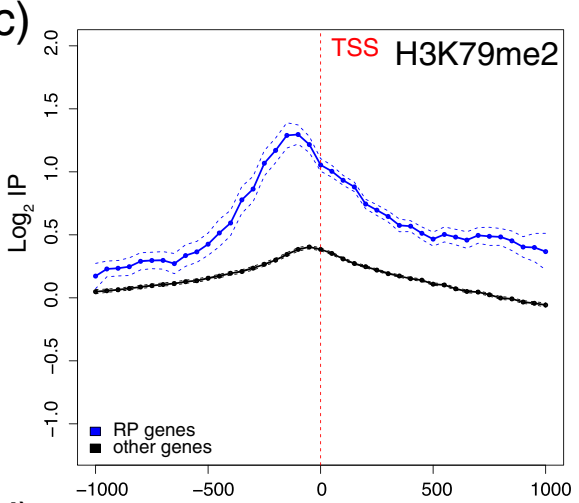

(d)
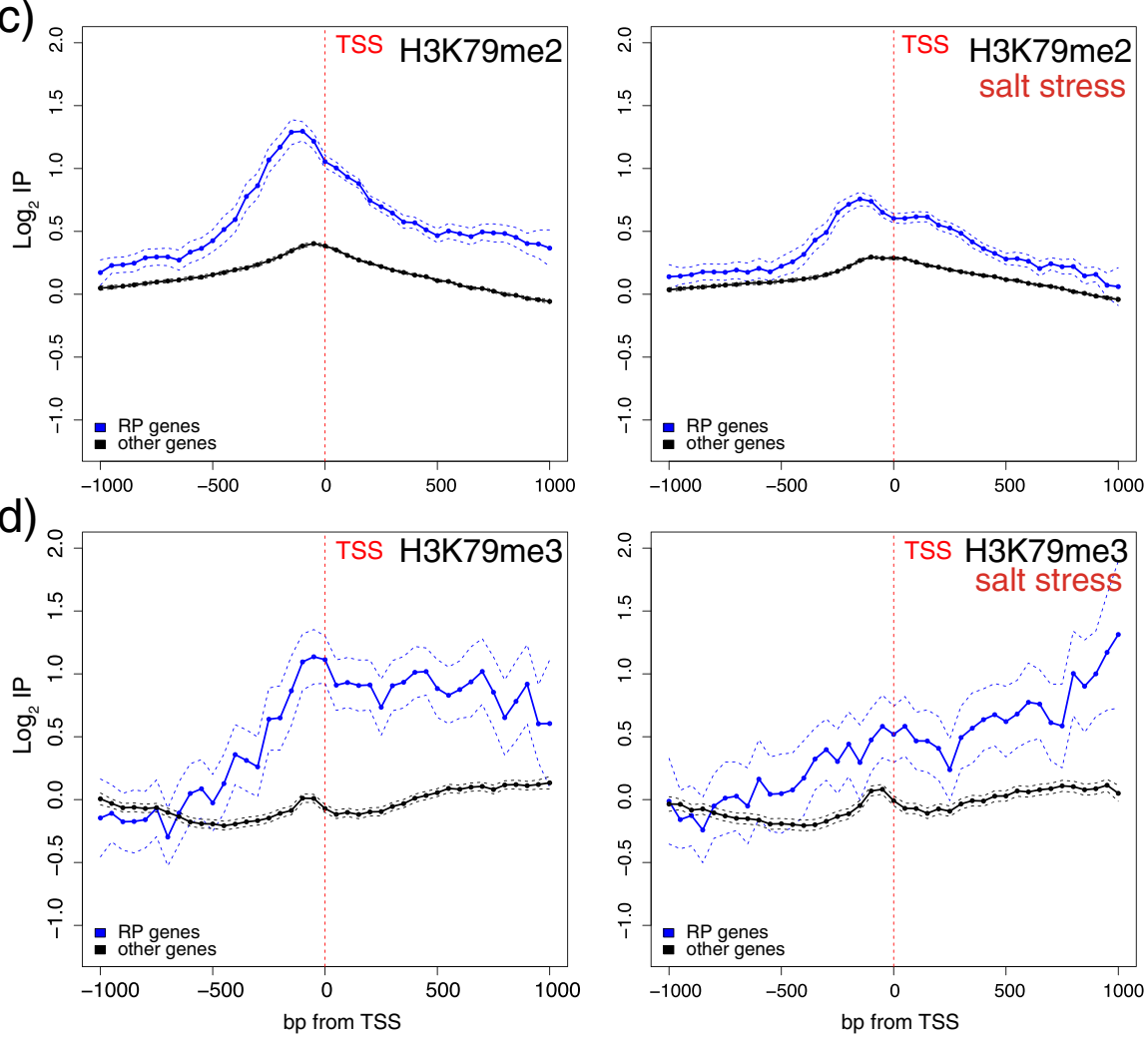

Figure 7 (See legend on next page.) 
ChIP with a core histone antibody. The antibodies (obtained from rabbit, ChIP Grade) recognizing the histone modifications were: $\alpha-\mathrm{H} 3 \mathrm{~K} 9 \mathrm{ac}$ (Upstate, 06-942), $\alpha$ H3K14ac (Upstate, 07-353), $\alpha-\mathrm{H} 3$ K4me1 (Abcam, 8895), $\alpha$-H3K4me3 (Abcam, 8580), $\alpha$-H3K36me3 (Abcam, 9050), $\alpha-\mathrm{H} 3 K 79 \mathrm{me} 2$ (Abcam, 3594), $\alpha$-H3K79me3 (Abcam, 2621), and $\alpha$-H4K8ac (Abcam, 15823). The antibodies used in the control channel in the ChIP-Chip procedure were $\alpha-\mathrm{H} 3$ (Abcam, 1791) for the modifications of the histone $\mathrm{H} 3$ experiments and $\alpha-\mathrm{H} 4$ (Abcam, 10158) for the modifications of the histone $\mathrm{H} 4$ experiments.

\section{Chromatin immunoprecipitation and osmotic stress}

We followed a protocol based on a previously described method [68]. A volume of $40 \mathrm{~mL}$ YPD culture from each one (O.D.600 $\approx 0.5-0.8)$ was set aside, and proteins were cross-linked to their target sites in vivo by adding formaldehyde at a final concentration of $1 \%$. Cells were incubated for $30 \mathrm{~min}$ at room temperature with occasional mixing, and cross-linking was quenched by adding glycine at a final concentration of $125 \mathrm{mM}$. Cells were washed 3 times with $30 \mathrm{~mL}$ of ice-cold PBS buffer $\left(140 \mathrm{mM} \mathrm{NaCl}, 2.7 \mathrm{mM} \mathrm{KCl}, 10 \mathrm{mM} \mathrm{Na} \mathrm{HPO}_{4}, 1.8 \mathrm{mM}\right.$ $\mathrm{KH}_{2} \mathrm{PO}_{4}$, pH 7.4). Pelleted cells were processed immediately or were frozen and stored at $-80^{\circ} \mathrm{C}$ for no longer than 1 week. Cells were thawed on ice and resuspended in $300 \mu \mathrm{L}$ of lysis buffer $(50 \mathrm{mM}$ HEPES-KOH $\mathrm{pH} 7.5$, $140 \mathrm{mM} \mathrm{NaCl}, 1 \mathrm{mM}$ EDTA, $1 \%$ Triton X-100, 0.1\% sodium deoxycholate, $1 \mathrm{mM}$ Phenylmethylsulfonyl fluoride (PMSF), $1 \mathrm{mM}$ benzamidine and 1 pill of protease inhibitor cocktail (Roche) was dissolved in every $25 \mathrm{~mL}$ of buffer). The equivalent of $0.2 \mathrm{~mL}$ of frozen glass beads (425-600 mm, Sigma) was added to the cellular suspension and cells were lysed at $4{ }^{\circ} \mathrm{C}$ for 45 min of vortexing in a Genie 2 vortex with Turbo mix at maximum power. The tube was bored with an incandescent needle at the bottom and placed over another eppendorf tube, and was centrifuged for a few seconds. Beads were washed with a further $400 \mu \mathrm{L}$ amount of lysis buffer. A final volume of approximately $700 \mu \mathrm{L}$ of extract was obtained. Sonication of DNA was performed to obtain DNA fragments of between 200-1000 bp, with an average size of $400 \mathrm{bp}$. Chromatin was sonicated on ice, 8 pulses of $30 \mathrm{~s}$ at an amplitude of $38 \%$ in a Vibracell VCX500 (Sonics\&Materials). Cell debris was removed by centrifugation at $13000 \mathrm{rpm}$ at $4^{\circ} \mathrm{C}$ for $10 \mathrm{~min}$. An $50-\mu \mathrm{L}$ aliquot $\mathrm{f}$ this whole cell extract was kept to check the quality and size of the isolated chromatin. The antibodies used were $15 \mu \mathrm{g}$ of rabbit $\alpha$-histone modified or $20 \mu \mathrm{g}$ of rabbit $\alpha$-histone unmodified. Rabbit antibody complexes were collected using $50 \mu \mathrm{L}$ of a suspension of sheep $\alpha$-rabbit IgG M-280 dynabeads (Dynal, Invitrogen Corp., Carlsbad, CA, USA) in a final volume of $120 \mu \mathrm{L}$. Suspensions were incubated overnight at $4^{\circ} \mathrm{C}$. The DNA fragments specifically cross-linked to the antibody were purified by immunoprecipitation with the indicated monoclonal antibodies coupled to dynabeads for $4 \mathrm{~h}$ at $4^{\circ} \mathrm{C}$. Beads were washed twice with lysis buffer, twice with $500 \mathrm{mM}$ of $\mathrm{NaCl}$ lysis buffer, twice with wash buffer (10 mM Tris-HCl pH 8.0, $250 \mathrm{mM} \mathrm{LiCl,} \mathrm{0.5 \%} \mathrm{Nonidet}$ P-40, 0.5\% sodium deoxycholate, $1 \mathrm{mM}$ EDTA pH 8.0, $1 \mathrm{mM}$ PMSF, $1 \mathrm{mM}$ benzamidine and 1 pill of protease inhibitor cocktail $/ 25 \mathrm{~mL}$ from Roche), once with $\mathrm{TE}$ containing $1 \mathrm{mM}$ PMSF, and were finally collected. Two successive elutions were performed with 100 and $150 \mu \mathrm{L}$ of elution buffer (50 mM Tris- $\mathrm{HCl}$ pH 8.0, $10 \mathrm{mM}$ EDTA, $1 \% \mathrm{SDS}$ ) by incubating $10 \mathrm{~min}$ at $65^{\circ} \mathrm{C}$ each time. The eluted fraction of the protein cross-linked to DNA was treated overnight at $65^{\circ} \mathrm{C}$ to reverse the cross-linking.

Osmotic stress $(0.4 \mathrm{M} \mathrm{NaCl})$ was produced by adding a small volume of concentrated $\mathrm{NaCl}$ solution to the yeast culture $10 \mathrm{~min}$ before cross-linking with formaldehyde.

\section{DNA purification and annealed linkers ligation}

Proteins were degraded by adding $50 \mu \mathrm{g}$ of proteinase $\mathrm{K}$ and SDS at a final concentration of $2.5 \%$ with incubation at $37^{\circ} \mathrm{C}$ for $1 \mathrm{~h}$. DNA was purified by phenol/chloroform/isoamylic alcohol extraction. The aqueous phase was subsequently purified with Montage PCR columns (Millipore). The total eluted volume was treated with $10 \mu \mathrm{g}$ of RNAse A for $30 \mathrm{~min}$ at $37^{\circ} \mathrm{C}$. Ethanol precipitation was performed in the presence of $20 \mu \mathrm{g}$ of glycogen as a carrier. Immunoprecipitated DNA was blunted by T4 phage DNA polymerase in a reaction volume of $124 \mu \mathrm{L}$ (T4 DNA Pol buffer, $40 \mu \mathrm{g} / \mu \mathrm{L}$ BSA, $80 \mu \mathrm{M}$ dNTPs, 0.6 U T4 DNA Polymerase from Roche). The reaction was allowed to proceed for $20 \mathrm{~min}$ at $12^{\circ} \mathrm{C}$. After phenol/chloroform/isoamylic alcohol extraction, DNA was ethanol-precipitated in the presence of $11 \mu \mathrm{g}$ of glycogen and was ligated in a final volume of $50 \mu \mathrm{L}$ with annealed linkers oJW102 and oJW103 (1.5 $\mu \mathrm{M}$ of each primer). The reaction was carried out overnight at $16^{\circ} \mathrm{C}$ and ligated DNA was precipitated. 


\section{DNA amplification and microarray hybridization}

Ligation-Mediated PCR was used for DNA amplification [68]. All the immunoprecipitated DNA was used for the LM-PCR reaction. Briefly, ligated DNA was dissolved in final volume of $40 \mu \mathrm{L}$ (1x Biotaq buffer from Bioline, $2 \mathrm{mM} \mathrm{MgCl} 2,0.25 \mathrm{mM}$ dNTPs, $1.25 \mu \mathrm{M}$ oligonucleotide oJW102). The reaction was started by incubating for $2 \mathrm{~min}$ at $55^{\circ} \mathrm{C}$ and was paused to add $10 \mu \mathrm{L}$ of the reaction mix (1X Biotaq buffer, $2 \mathrm{mM} \mathrm{MgCl} 2$ and $5 \mathrm{U}$ BioTaq from Bioline). The program was resumed as so: $5 \mathrm{~min}$ at $72^{\circ} \mathrm{C}$, 2 min at $95^{\circ} \mathrm{C}$ and 33 cycles of $30 \mathrm{~s}$ at $95^{\circ} \mathrm{C}, 30 \mathrm{~s}$ at $55^{\circ} \mathrm{C}$ and 2 min at $72^{\circ} \mathrm{C}$. A $5-\mu \mathrm{L}$ DNA aliquot of the LM-PCR was analyzed on a $1.2 \%$ agarose gel to check for a smear and an average size of $150 \mathrm{bp}$. The rest was purified with Montage PCR columns. DNA was precipitated overnight and resuspended in $25 \mu \mathrm{L}$ of milliQ water. Amplified samples were quantified and purity was confirmed by spectrometry (NanoDrop ND1000, NanoDrop Technologies, Wilmington, Delaware, USA). The expected fragment size was confirmed in a DNA 75002100 Bioanalyzer (Agilent Technologies, Palo Alto, California, USA) assay. DNA labeling was obtained following the 'Agilent Yeast ChIP-onchip Analysis' protocol, version 9.2 (Agilent Technologies, Palo Alto, California, USA, p/n G4493-90010). Then 2000 ng of ChIP and reference IP (core histone H3 or H4) samples were respectively labeled with Cyanine 5-dUTP and cyanine 3-dUTP using the 'CGH Labeling Kit' (Invitrogen, $\mathrm{p} / \mathrm{n}$ 18095-011) following the manufacturer's instructions. Labeled DNA was hybridized to the Yeast Whole Genome ChIP-on-chip Microarray (Agilent $\mathrm{p} / \mathrm{n}$ G4491A, AMADID: 014741), specifically designed for location analyses. The average probe spatial resolution was $\sim 50 \mathrm{nt}$ and it contained $\sim 85 \%$ of the non repetitive portion of the yeast genome sourced from yeast sacCer1 ( 12 MB). Arrays were scanned in an Agilent Microarray Scanner (Agilent G2565BA) in accordance with the manufacturer's protocol. Data were extracted using the Agilent Feature Extraction Software, v10.10.1.1, following the Agilent protocol ChIP_1010_Sep10, grid template 014741_D_F_20091202 and metric set ChIP_QCMT_Sep10.

\section{Data analysis}

Data were processed by ChIP Analytics 1.3 (Agilent). Blank subtraction normalization, inter-array median normalization and intra-array median normalization were performed. Probes were lifted over to the sacCer3 genome version (April2011). Transcript boundaries [38] were downloaded from SGD (R64-1-1, http://www.yeastgenome.org). Raw and processed data were deposited at GEO (reference GSE41587).

Plots were performed using $\mathrm{R}$ and bioconductor [69]. Probes were binned to $50 \mathrm{bp}$ or $100 \mathrm{bp}$, and the mean and confidence intervals for the means (t-test 95\% confidence) were plotted. For the metagene representation, each transcript was forced to a virtual length of $1000 \mathrm{bp}$, and a $100 \mathrm{bp}$ bin was applied.

\section{Additional files}

\begin{abstract}
Additional file 1: Figure S1. The profiles of H3K9ac (a), H3K14ac (b) and $\mathrm{H} 4 \mathrm{~K} 8 \mathrm{ac}$ (c) in relation to the levels of core histone $\mathrm{H3}(\mathrm{a}, \mathrm{b})$ or $\mathrm{H} 4$ (c) genome-wide using a metagene representation. The log2 values of the specific immunoprecipitation of the modified histone were represented in relation to the immunoprecipitation of core histone $\mathrm{H} 3$. For the metagene representation, each transcript was forced to a virtual length of $1000 \mathrm{bp}$, and a $100 \mathrm{bp}$ bin was applied, while the data relating to the 5'UTR and $3^{\prime} U T R$ regions corresponded to actual distances, each with a 100-bp unit. The mean and confidence intervals for the means (t-test, 95\% confidence) were plotted. Each experiment compared a ChIP with a histone modification antibody to a control ChIP with a core histone antibody.
\end{abstract}

Additional file 2: Figure S2. The profiles H3K4me1 (a), H3K4me3 (b), H3K36me3 (c), H3K79me2 (d) and H3K79me3 (e) in relation to the levels of core histone $\mathrm{H} 3$, genome-wide. The log2 values of the specific immunoprecipitation of the modified histone were represented in relation to the immunoprecipitation of core histone $\mathrm{H} 3$. Data were represented as in Figure 1.

Additional file 3: Figure S3. The profiles of H3K14ac (a), H4K8ac (b), H3K4me1 (c), H3K4me3 (d), H3K36me3 (e), H3K79me2 (f) and H3K79me3 (g) in relation to the levels of core histone $\mathrm{H} 3 \mathbf{( a ,} \mathbf{c}, \mathbf{d}, \mathbf{e}, \mathbf{f}, \mathbf{g})$ or $\mathrm{H} 4$ (b) of the genes grouped according to presence or absence of a TATA box on the gene.

Additional file 4: Figure S4. The profiles of H3K14ac (a), H4K8ac (b) H3K4me1 (c), H3K4me3 (d), H3K36me3 (e), H3K79me2 (f) and H3K79me3 (g) in relation to the levels of core histone $\mathrm{H}_{3}(\mathbf{a}, \mathbf{c}, \mathbf{d}, \mathbf{e}, \mathbf{f}, \mathbf{g})$ or $\mathrm{H} 4$ (b) of the genes grouped according to the distribution of RNA pol II [46] on the gene.

Additional file 5: Table S1. Compares the mRNA amount, indirect transcription rate, nascent transcription rate and RNA pol II occupancy data with the level of the eight histone modifications studied in both the promoters region and ORFs.

Additional file 6: Table S2. The 248 up-regulated and the 400 down-regulated osmo-responsive genes.

\section{Abbreviations}

ChIP: Chromatin immunoprecipitation; ChIP-Chip: Chromatin immunoprecipitation coupled to microarray detection of DNA immunoprecipitated; H3K4me1: Lysine 4 of histone $\mathrm{H} 3$ mono-methylated; H3K4me2: di-methylated; H3K4me3: tri-methylated; H3K36me3: Lysine 36 of histone $\mathrm{H3}$ tri-methylated; H3K79me2: Lysine 79 of histone $\mathrm{H3}$ di-methylated; H3K79me3: tri-methylated; H3K9ac: Lysine 9 of histone H3 acetylated;

H3K14ac: Lysine 14 of histone H3 acetylated; H4K8ac: Lysine 8 of histone H4 acetylated; TSS: Transcription start site; NDR: Nucleosome depleted region; ORF: Open reading frame; SAGA: Spt-Ada-Gen5 acetyltransferase; RNA pol II: RNA polymerase II; RP: Ribosomal proteins; NDR: Nucleosome depleted region; CTD: Carboxy terminal domain; PMSF: Phenylmethylsulfonyl fluoride.

\section{Competing interests}

The authors declare that they have no competing interests.

\section{Authors' contributions}

LM-P and MDC performed the experiments. VP analyzed the data and wrote the paper. VT conceived, designed and performed the experiments, and wrote the paper. All the authors read and approved the manuscript.

\section{Acknowledgements}

The authors are indebted to Christophe Chabbert and J.E. Pérez-Ortín for helpful discussions and their critical reading of the manuscript. This work has been supported by Research Grant BFU2008-01976 BMC to VT from the Spanish Ministry of Science and Innovation and by the Generalitat Valenciana 
Grant (Prometeo 2011/088), Spain to J.E.P-O. VP was supported by a fellowship for Specialization in International Organisms (EOI, from the Spanish Ministry of Science and Innovation) and an EMBO long-term fellowship.

\section{Author details}

'Departament de Bioquímica i Biologia Molecular, Universitat de València, C/Dr. Moliner 50, 46100 Burjassot, València, Spain. ${ }^{2}$ Genome Biology Unit, European Molecular Biology Laboratory, Heidelberg, Germany.

Received: 19 February 2013 Accepted: 24 March 2014

Published: 30 March 2014

\section{References}

1. Bannister AJ, Kouzarides T: Regulation of chromatin by histone modifications. Cell Res 2011, 21:381-395.

2. Shogren-Knaak M, Ishii H, Sun JM, Pazin MJ, Davie JR, Peterson CL: Histone H4-K16 acetylation controls chromatin structure and protein interactions. Science 2006, 311:844-847.

3. Turner BM: Decoding the nucleosome. Cell 1993, 75:5-8.

4. Tordera V, Sendra R, Pérez-Ortín JE: The role of histones and their modifications in the informative content of chromatin. Experientia 1993, 49:780-788.

5. Strahl $B D$, Allis $C D$ : The language of covalent histone modifications. Nature 2000, 403:41-45.

6. Jenuwein T, Allis CD: Translating the histone code. Science 2001, 293:1074-1080.

7. Berger SL: The complex language of chromatin regulation during transcription. Nature 2007, 447:407-412.

8. Bernstein BE, Humphrey EL, Erlich RL, Schneider R, Bouman P, Liu JS, Kouzarides T, Schreiber SL: Methylation of histone H3 Lys 4 in coding regions of active genes. Proc Natl Acad Sci U S A 2002, 99:8695-8700.

9. Kurdistani SK, Tavazoie S, Grunstein M: Mapping global histone acetylation patterns to gene expression. Cell 2004, 117:721-733.

10. Lee CK, Shibata Y, Rao B, Strahl BD, Lieb JD: Evidence for nucleosome depletion at active regulatory regions genome-wide. Nat Genet 2004, 36:900-905

11. Liu CL, Kaplan T, Kim M, Buratowski S, Schreiber SL, Friedman N, Rando OJ: Single-nucleosome mapping of histone modifications in S. cerevisiae. PLoS Biol 2005, 3(10):e328.

12. Pokholok DK, Harbison CT, Levine S, Cole M, Hannett NM, Lee TI, Bell GW, Walker K, Rolfe PA, Herbolsheimer E, Zeitlinger Lewitter JF, Gifford DK, Young RA: Genome-wide map of nucleosome acetylation and methylation in yeast. Cell 2005, 122:517-527.

13. Henikoff S, Shilatifard A: Histone modification: cause or cog? Trends Genet 2011, 27:389-396.

14. Rando OJ, Chang HY: Genome-wide views of chromatin structure. Annu Rev Biochem 2009, 78:245-271.

15. Kirmizis A, Santos-Rosa H, Penkett CJ, Singer MA, Vermeulen M, Mann M, Bähler J, Green RD, Kouzarides T: Arginine methylation at histone H3R2 controls deposition of H3K4 trimethylation. Nature 2007, 449:928-932.

16. Schulze JM, Jackson J, Nakanishi S, Gardner JM, Hentrich T, Haug J, Johnston M, Jaspersen SL, Kobor MS, Shilatifard A: Linking cell cycle to histone modifications: $\mathrm{SBF}$ and $\mathrm{H} 2 \mathrm{~B}$ monoubiquitination machinery and cell cycle regulation of H3K79 dimethylation. Mol Cell 2009, 35:626-641.

17. Guillemette $B$, Drogaris $\mathrm{P}$, Lin $\mathrm{H}-\mathrm{HS}$, Armstrong $\mathrm{H}$, Hiragami-Hamada $\mathrm{K}$, Imhof A, Bonneil E, Thibault P, Verreault A, Festenstein RJ: H3 lysine 4 is acetylated at active gene promoters and is regulated by $\mathrm{H} 3$ lysine 4 methylation. PLoS Genet 2011, 7(3):e1001354.

18. Batta K, Zhang Z, Yen K, Goffman DB, Pugh BF: Genome-wide function of H2B ubiquitylation in promoter and genic regions. Genes Dev 2011, 25:2254-2265.

19. Lee J-S, Garrett AS, Yen K, Takahashi Y-H, Hu D, Jackson J, Seidel C, Pugh BF, Shilatifard A: Codependency of H2B monoubiquitination and nucleosome reassembly on Chd1. Genes Dev 2012, 26:914-919.

20. Brownell JE, Zhou J, Ranalli T, Kobayashi R, Edmondson DG, Roth SY, Allis CD: Tetrahymena histone acetyltransferase A: a homolog to yeast Gcn5p linking histone acetylation to gene activation. Cell 1996, 84:843-851.

21. Robert F, Pokholok DK, Hannett NM, Rinaldi NJ, Chandy M, Rolfe A, Workman JL, Gifford DK, Young RA: Global position and recruitment of HATs and HDACs in the yeast genome. Mol Cell 2004, 16:199-209.
22. Rosaleny LE, Ruiz-García AB, García-Martínez J, Pérez-Ortín JE, Tordera V: The Sas3p and Gcn5p histone acetyltransferases are recruited to similar genes. Genome Biol 2007, 8(6):R119.

23. Utley RT, Ikeda K, Grant PA, Côté J, Steger DJ, Eberharter A, John S, Workman JL: Transcriptional activators direct histone acetyltransferase complexes to nucleosomes. Nature 1998, 394:498-502.

24. Ikeda K, Steger DJ, Eberharter A, Workman JL: Activation domain-specific and general transcription stimulation by native histone acetyltransferase complexes. Mol Cell Biol 1999, 19:855-863.

25. Allard S, Utley RT, Savard J, Clarke A, Grant P, Brandl CJ, Pillus L, Workman $J \mathrm{~L}$, Côté J: NuA4, an essential transcription adaptor/histone $\mathrm{H} 4$ acetyltransferase complex containing Esa1p and the ATM-related cofactor Tra1p. EMBO J 1999, 18:5108-5119.

26. Briggs SD, Bryk M, Strahl BD, Cheung WL, Davie JK, Dent SY, Winston F, Allis $\mathrm{CD}$ : Histone $\mathrm{H} 3$ lysine 4 methylation is mediated by Set 1 and required for cell growth and rDNA silencing in Saccharomyces cerevisiae. Genes Dev 2001, 15:3286-3295.

27. Roguev A, Schaft D, Shevchenko A, Pijnappel WW, Wilm M, Aasland R, Stewart AF: The Saccharomyces cerevisiae Set1 complex includes an Ash2 homologue and methylates histone 3 lysine 4. EMBO J 2001, 20:7137-7148

28. Krogan NJ, Dover J, Khorrami S, Greenblatt JF, Schneider J, Johnston M, Shilatifard A: COMPASS, a histone H3 (Lysine 4) methyltransferase required for telomeric silencing of gene expression. J Biol Chem 2002, 277:10753-10755.

29. Ng HH, Robert F, Young RA, Struhl K: Targeted recruitment of Set1 histone methylase by elongating Pol II provides a localized mark and memory of recent transcriptional activity. Mol Cell 2003, 11:709-719.

30. Santos-Rosa H, Schneider R, Bannister AJ, Sherriff J, Bernstein BE, Emre NC, Schreiber SL, Mellor J, Kouzarides T: Active genes are tri-methylated at K4 of histone H3. Nature 2002, 419:407-411.

31. Nagy PL, Griesenbeck J, Kornberg RD, Cleary ML: A trithorax-group complex purified from Saccharomyces cerevisiae is required for methylation of histone H3. Proc Natl Acad Sci U S A 2002, 99:90-94.

32. Strahl BD, Grant PA, Briggs SD, Sun ZW, Bone JR, Caldwell JA, Mollah S, Cook RG, Shabanowitz J, Hunt DF, Allis CD: Set2 is a nucleosomal histone $\mathrm{H} 3$-selective methyltransferase that mediates transcriptional repression. Mol Cell Biol 2002, 22:1298-1306.

33. Lacoste N, Utley RT, Hunter JM, Poirier GG, Côte J: Disruptor of telomeric silencing- 1 is a chromatin specific histone H3 methyltransferase. J Biol Chem 2002, 277:30421-30424.

34. van Leeuwen F, Gafken PR, Gottschling DE: Dot1p modulates silencing in yeast by methylation of the nucleosome core. Cell 2002, 109:745-756.

35. $\mathrm{Ng} \mathrm{HH}$, Feng $\mathrm{Q}$, Wang $\mathrm{H}$, Erdjument-Bromage $H$, Tempst $P$, Zhang $Y$, Struh $\mathrm{K}$ : Lysine methylation within the globular domain of histone $\mathrm{H} 3$ by Dot1 is important for telomeric silencing and Sir protein association. Genes Dev 2002, 16:1518-1527.

36. Feng $\mathrm{Q}$, Wang $\mathrm{H}, \mathrm{Ng} \mathrm{HH}$, Erdjument-Bromage $\mathrm{H}$, Tempst P, Struhl K, Zhang $\mathrm{Y}$ : Methylation of $\mathrm{H} 3$-lysine 79 is mediated by a new family of HMTases without a SET domain. Curr Biol 2002, 12:1052-1058.

37. Morillon A, Karabetsou N, Nair A, Mellor J: Dynamic lysine methylation on histone $\mathrm{H} 3$ defines the regulatory phase of gene transcription. Mol Cell 2005, 18:723-734.

38. Xu Z, Wei W, Gagneur J, Perocchi F, Clauder-Münster S, Camblong J, Guffanti E, Stutz F, Huber W, Steinmetz LM: Bidirectional promoters generate pervasive transcription in yeast. Nature 2009, 457:1033-1037.

39. Xue-Franzén Y, Johnsson A, Brodin D, Henriksson J, Bürglin TR, Wright AP: Genome-wide characterisation of the Gcn5 histone acetyltransferase in budding yeast during stress adaptation reveals evolutionarily conserved and diverged roles. BMC Genomics 2010, 11:200.

40. Johnsson A, Durand-Dubief M, Xue-Franzén Y, Rönnerblad M, Ekwall K, Wright A: HAT-HDAC interplay modulates global histone H3K14 acetylation in gene-coding regions during stress. EMBO Rep 2009, 10:1009-1014

41. Pelechano V, Chávez S, Pérez-Ortín JE: A Complete set of nascent transcription rates for yeast genes. PLOS ONE 2010, 5(11):e15442.

42. Sun M, Schwalb B, Schulz D, Pirkl N, Etzold S, Larivière L, Maier KC, Seizl M, Tresch A, Cramer P: Comparative dynamic transcriptome analysis (CDTA) reveals mutual feedback between mRNA synthesis and degradation. Genome Res 2012, 22:1350-1359. 
43. Yuan GC, Liu YJ, Dion MF, Slack MD, Wu LF, Altschuler SJ, Rando OJ: Genome-scale identification of nucleosome positions in S. cerevisiae. Science 2005, 309:626-630

44. Albert I, Mavrich TN, Tomsho LP, Qi J, Zanton SJ, Schuster SC, Pugh BF: Translational and rotational settings of H2A.Z nucleosomes across the Saccharomyces cerevisiae genome. Nature 2007, 446:572-576.

45. Zaugg JB, Luscombe NM: A genomic model of condition-specific nucleosome behavior explains transcriptional activity in yeast. Genome Res 2012, 22:84-94.

46. Venters BJ, Pugh BF: A canonical promoter organization of the transcription machinery and its regulators in the Saccharomyces genome. Genome Res 2009, 19:360-371.

47. Dehé P-M, Pamblanco M, Luciano P, Lebrun R, le Moinier D, Sendra R, Verreault A, Tordera V, Géli V: Histone H3 lysine 4 mono-methylation does not require ubiquitination of histone H2B. J Mol Biol 2005, 353:477-484.

48. Jasiak AJ, Hartmann H, Karakasili E, Kalocsay M, Flatley A, Kremmer E, Strässer K, Martin DE, Söding J, Cramer P: Genome-associated RNA polymerase II includes the dissociable Rpb4/7 subcomplex. J Biol Chem 2008, 283:26423-26427.

49. Holstege FC, Jennings EG, Wyrick JJ, Lee TI, Hengartner CJ, Green MR, Golub TR, Lander ES, Young RA: Dissecting the regulatory circuitry of a eukaryotic genome. Cell 1998, 95:717-728.

50. Steger DJ, Lefterova MI, Ying L, Stonestrom AJ, Schupp M, Zhuo D, Vakoc AL, Kim JE, Chen J, Lazar MA, Blobel GA, Vakoc CR: DOT1L/KMT4 recruitment and $\mathrm{H} 3 \mathrm{~K} 79$ methylation are ubiquitously coupled with gene transcription in mammalian cells. Mol Cell Biol 2008, 28:2825-2839.

51. Yun M, Wu J, Workman JL, Li B: Readers of histone modifications. Cell Res 2011, 21:564-578.

52. de Nadal E, Posas F: Multilayered control of gene expression by stress-activated protein kinases. EMBO J 2010, 29:4-13.

53. Rep M, Krant M, Thevelein JM, Hohmann S: The transcriptional response of Saccharomyces cerevisiae to osmotic shock. J Biol Chem 2000, 275:8290-8300.

54. Posas F, Chambersi JR, Heymani JA, Hoeffleri JP, de Nadal E, Ariño J: The transcriptional response of yeast to saline stress. J Biol Chem 2000, 275:17249-17255.

55. Romero-Santacreu L, Moreno J, Pérez-Ortín JE, Alepuz P: Specific and global regulation of mRNA stability during osmotic stress in Saccharomyces cerevisiae. RNA 2009, 15:1110-1120.

56. García-Martínez J, Aranda A, Pérez-Ortín JE: Genomic run-on evaluates transcription rates for all yeast genes and identifies gene regulatory mechanisms. Mol Cell 2004, 15:303-313.

57. de Nadal E, Zapater M, Alepuz PM, Sumoy L, Mas G, Posas F: The MAPK Hog1 recruits Rpd3 histone deacetylase to activate osmoresponsive genes. Nature 2004, 427:370-374

58. Waterborg JH: Dynamics of histone acetylation in Saccharomyces cerevisiae. Biochemistry 2001, 40:2599-2605.

59. Weiner A, Hughes A, Yassour M, Rando OJ, Friedman N: High-resolution nucleosome mapping reveals transcription-dependent promoter packaging. Genome Res 2010, 20:90-100.

60. Pelechano V, Jimeno-González S, Rodríquez-Gil A, García-Martínez J, Pérez-Ortín JE, Chávez S: 11. Regulon-specific control of transcription elongation across the yeast genome. PLoS Genet 2009, 5(8):e1000614.

61. Suka N, Suka Y, Carmen AA, Wu J, Grunstein M: Highly specific antibodies determine histone acetylation site usage in yeast heterochromatin and euchromatin. Mol Cell 2001, 8:473-479.

62. Zapater M, Sohrmann M, Peter M, Posas F, de Nadal E: Selective requirement for SAGA in hog1-mediated gene expression depending on the severity of the external osmostress conditions. Mol Cell Biol 2007. 27:3900-3910.

63. Weiner A, Chen HV, Liu CL, Rahat A, Klien A, Soares L, Gudipati M, Pfeffner J, Regev A, Buratowski S, Pleiss JA, Friedman N, Rando OJ: Systematic dissection of roles for chromatin regulators in a yeast stress response. PLOS Biol 2012, 10:e1001369.

64. Taverna SD, llin S, Rogers RS, Tanny JC, Lavender H, Li H, Baker L, Boyle J, Blair LP, Chait BT, Patel DJ, Aitchison JD, Tackett AJ, Allis CD: Yng1 PHD finger binding to $\mathrm{H} 3$ trimethylated at $\mathrm{K} 4$ promotes NuA3 HAT activity at K14 of H3 and transcription at a subset of targeted ORFs. Mol Cell 2006, 24:785-796.
65. Pray-Grant MG, Daniel JA, Schieltz D, Yates JR 3rd, Grant PA: Chd1 chromodomain links histone $\mathrm{H} 3$ methylation with SAGA- and SLIK-dependent acetylation. Nature 2005, 433:434-438.

66. Nakanishi S, Sanderson BW, Delventhal KM, Bradford WD, Staehling Hampton K, Shilatifard A: A comprehensive library of histone mutants identifies nucleosomal residues required for $\mathrm{H} 3 \mathrm{~K} 4$ methylation. Nat Struct Mol Biol 2008, 15:881-888.

67. Maltbya VE, Martina BJE, Brind'Amourb J, Chruscickia AT, McBurneya KL, Schulzec JM, Johnsona IJ, Hillsd M, Hentrichc T, Koborc MS, Lorinczb MC, Howe L: Histone H3K4 demethylation is negatively regulated by histone H3 acetylation in Saccharomyces cerevisiae. Proc Natl Acad Sci U S A 2012, 109:18505-18510.

68. Ren B, Robert F, Wyrick JJ, Aparicio O, Jennings EG, Simon I, Zeitlinger J, Schreiber J, Hannett N, Kanin E, Volkert TL, Wilson CJ, Bell SP, Young RA: Genome-wide location and function of DNA binding proteins. Science 2000, 290:2306-2309.

69. Gentleman RC, Carey VJ, Bates DM, Bolstad B, Dettling M, Dudoit S, Ellis B, Gautier L, Ge Y, Gentry J, Hornik K, Hothorn T, Huber W, lacus S, Irizarry R, Leisch F, Li C, Maechler M, Rossini AJ, Sawitzki G, Smith C, Smyth G, Tierney L, Yang JY, Zhang J: Bioconductor: open software development for computational biology and bioinformatics. Genome Biol 2004, 5:R80

doi:10.1186/1471-2164-15-247

Cite this article as: Magraner-Pardo et al:: Dynamic remodeling of histone modifications in response to osmotic stress in Saccharomyces cerevisiae. BMC Genomics 2014 15:247.

\section{Submit your next manuscript to BioMed Central and take full advantage of:}

- Convenient online submission

- Thorough peer review

- No space constraints or color figure charges

- Immediate publication on acceptance

- Inclusion in PubMed, CAS, Scopus and Google Scholar

- Research which is freely available for redistribution

Submit your manuscript at www.biomedcentral.com/submit
C) BioMed Central 